\title{
A STUDY OF INTESTINAL OBSTRUCTION CONSERVTIVE VERSUS SURGICAL MANAGEMENT
}

\author{
MA Oyinlola ${ }^{1} \&$ OA Omisakin ${ }^{2}$
}

${ }^{1}$ The College of Medicine, Lagos State University, Nigeria

${ }^{2}$ The College of Medicine, Lagos State University, Nigeria

*Corresponding Author: MA Oyinlola

Article Received: 12-05-19

Accepted: 23-09-19
Published: 05-10-19

Licensing Details: Author retains the right of this article. The article is distributed under the terms of the $\begin{array}{lllll}\text { Creative } & \text { Commons } & \text { Attribution-NonCommercial } & 4.0 & \text { License }\end{array}$ (http://www.creativecommons.org/licences/by-nc/4.0/) which permits non-commercial use, reproduction and distribution of the work without further permission provided the original work is attributed as specified on the Journal open access page

\begin{abstract}
Intestinal obstruction refers to the impairment to the abnormal passage of intestinal contents which can be due to the mechanical obstruction or failure of normal intestinal motility in the absence of an obstructing lesion. Extra luminal, intrinsic, and intraluminal are three categories of small bowel obstruction. In this retrospective observational study, patients presenting to the A\&E department of surgery unit who had similar condition were screened. The study is based on total of 60 patients out of which 22 patients managed conservatively whereas 38 patients were managed surgically. Common symptoms were abdominal pain and vomiting. Based on physical findings, 42 patients had abdominal tenderness, 48 had abdominal distension, 44 had exaggerated bowel sound, 2 patient had abdominal lump on palpation, and 2 patient had visible bowel loop. Surgically managed duration was 2.8 days on average. Mean duration for conservatively managed patients was 2.9 days. Among the surgically managed patients, 11 had strictures, 14 had adhesion, 8 had obstructed hernia, 1 had intussusception, and 4 had abdominal TB. Based on the cause of the obstruction, surgical procedure was carried out. History of abdominal surgery was found to be more frequent in whom obstruction was relieved conservatively. The conclusion of the study is that adhesions based on previously conducted surgery are important causes of SBO. Two common method of managing the condition is conservative management and surgical management. The criteria for utilizing particular method
\end{abstract}


is based on several patient related factors. Clinical decisions guide the management of SBO and timing of surgical intervention.

Keywords: Obstruction, Adhesion, Dynamic Obstruction,

\section{INTRODUCTION}

Intestinal obstruction can be defined as impairment to the abnormal passage of intestinal contents that may be due to either mechanical obstruction or failure of normal intestinal motility in the absence of an obstructing lesion. It is characterized by absence of passage of flatus and/or feces beyond 6-12 hrs. patient mostly experience vomiting, abdominal distension and colicky abdominal pain $[1,2,3,4,5,6]$ it can be developed due to the acute obstruction and relieved itself after sometime or may need some conservative management. The description of patients presenting with small bowel obstruction dates back to the 3rd or 4th century, when Praxagoras created an enterocutaneous fistula to relieve a bowel obstruction.

Even though, the surgery was considered as successful option, still nonoperative techniques were common for reducing laxatives, hernias, ingestions of heavy metals and leeches to remove toxic agents from the blood until late 18th century. So far, our understanding is that bowel obstruction is caused because of the following reasons.

- Obstruction arising from extraluminal adhesions, hernias, carcinomas, and abscesses.

- Obstruction intrinsic to the bowel wall (e.g., primary tumors).

- Intraluminal obturator obstruction (e.g., gallstones, enteroliths, foreign bodies, and bezoars).

Dynamic (mechanical) or adynamic (pseudoobstruction) are classification of large bowel obstructions. Mechanical obstruction is characterized by blockage of the large bowel (luminal, mural, or extramural), resulting in increased intestinal contractility as a physiologic response to relieve the obstruction. Intestinal obstruction-based patients are quite ill and may need regular evaluation, and monitoring of clinical and vital progress to determine when the surgical intervention will be suitable.

\section{Objectives}

In this study, objectives are as follows;

To study the clinical profile and clinical features of patients presenting with acute intestinal obstruction (AIO).

To study the role of investigations in diagnosis of AIO. To find out the underlying cause of AIO in patients under study.

To study the predictors of relief of symptoms in patients with AIO.

To study the indications and timing for surgery for AIO.

To follow-up the progress of patients and find out the outcome of management. 


\section{MATERIALS AND METHODS}

The study is based on a major hospital located in a major Nigerian city. The study consists of total of 60 patients. Patients having the abdominal pain were asked questions based on predesigned questionnaire. The inclusion criteria for this study was patients coming to the hospital with intestinal obstruction which is judged by abdominal pain, increased bowel sound, tenderness distension, dehydration, and constipation. All patients were briefed about the objectives of the study and written consent was taken. Those patients who were not fit for surgery or not willing to take part in the study were removed.

The methodology of the study is based on retrospective observational study. Patients who came to the hospital Accident and Emergency department were screened to identify the patients with AIO.

\section{Methodology}

This is a retrospective observational study. All patients presenting to the Emergency and Outpatient Department of surgery unit with features of intestinal obstruction were screened to identify the patients with AIO. Informed consent was obtained from the patients for inclusion in the study.

Brief interviews of patients were taken and their complaints, illness history details, previous other medical history, co-morbid related conditions, surgery history/ previous treatment, were recorded on a pre-specified data sheet. Clinical findings related to blood sugar, hemogram, urine routine and microscopy, serum electrolytes were also recorded side by side.

Mostly, the history consisted of presenting complaints including pain and its character, abdominal distension, vomiting, flatus and passage of faces. Inquiry also consisted of related illness in past, any abdominal related surgery in past, and any known abdominal illnesses.

Clinical examination undertook and focused on fever and abdominal signs like abdominal distension, presence of papable/visible bowel loops, bowel sound nature and lumps, and tachycardia presence. Digital rectal examination was done for all patients and its finding is also noted. Abdomen plain X-ray in the form of supine posture and erect posture were conducted and multiple air-fluid levels presence is noted along with colonic gas and dilated bowel loops.

Consistent with clinical assessment and investigations, initially conservative management was initiated. Patients' oral intake was withheld, nasogastric tube was inserted for aspiration of gastrointestinal secretions, intra-venous fluids were administered. If there were Electrolyte imbalance, so they were corrected.

Observations were made regarding relief of obstruction such as reduced vomiting, passage of feces/flatus, pain score, reduced abdominal girth and tenderness, reduced nasogastric tube output, and disappearance of palpable bowel loops. Regular monitoring was made in patients for signs of strangulation, viz, tachycardia, abdominal tenderness, fever, and so on. In case of strangulation indications, emergency-based operation was made. If the patient did not get relieved conservatively within a few hours of observation, exploratory laparotomy was performed. 
If patient condition is improved within few hours of conservative treatment, so further investigation is made regarding previous similar history or relevant symptoms. CT scan abdomen, ultrasound of the abdomen and pelvis, and other special investigations are made in order to look further findings of suggestive of intestinal obstruction and specific signs which suggest cause of obstruction.

In case the investigation provided sufficient information to confirm the diagnosis of a lesion explaining the symptoms of AIO in the patient, appropriate operation intervention was undertaken. In case the investigation failed to provide required information, the next investigation was undertaken.

\section{RESULTS AND DISCUSSION}

The study is based on observation of 60 patients who are evaluated in a public hospital in Nigeria and were related acute intestinal obstruction. 22 patients were managed conservatively while 38 patients were managed surgically. The average age of patients was 54 and there were 35 male and 25 females.

Table 1: Patient Age Details

\begin{tabular}{|c|c|}
\hline Age Interval & Patients \\
\hline $20-30$ & 5 \\
\hline $31-40$ & 12 \\
\hline $41-50$ & 15 \\
\hline $51-60$ & 12 \\
\hline $61-70$ & 8 \\
\hline $71-80$ & 8 \\
\hline
\end{tabular}

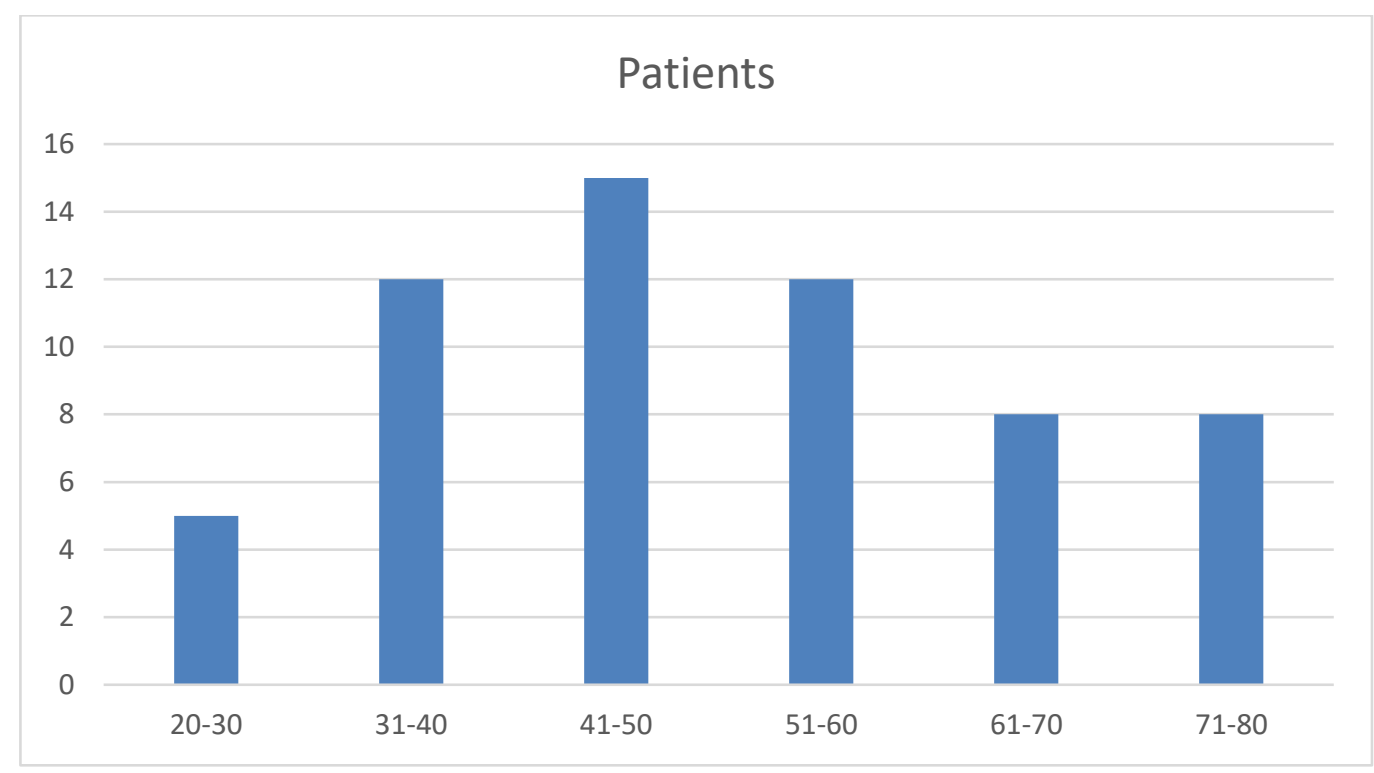

Figure 1: Age Distribution 
Common symptoms experienced by these patients included abdominal pain, vomiting, followed by obstipation. All patients who were managed conservatively had abdominal pain. Furthermore, 22 patient had obstipation and 20 patient had vomiting. In surgically managed patients, 44 had obstipation and 42 had vomiting. Based on physical findings, 42 patients had abdominal tenderness, 48 had abdominal distension, 44 had exaggerated bowel sound, 2 patient had abdominal lump on palpation, and 2 patient had visible bowel loop.

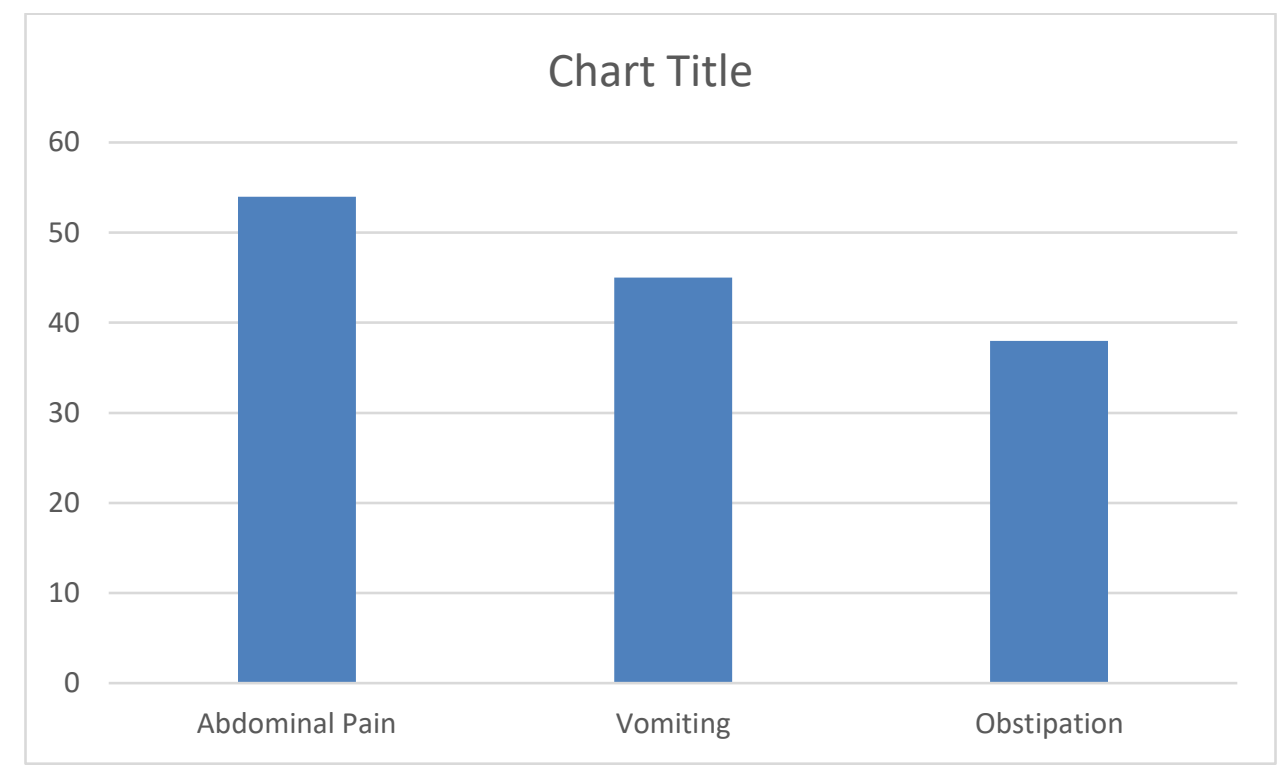

Figure 2: Symptoms and Physical Findings

Among this 60 patients, 54 patients had previous abdominal surgery, 44 patient had exploratory laparotomy for abdominal trauma, perforation, gynaec procedure, appendicectomy, etc. 6 patient developed features of obstruction following laproscopic T.L. among these patients, 8 were managed conservatively and 23 patient undergo surgery.

Table 2: CT Scan Findings

\begin{tabular}{|l|c|}
\hline CT Scan Finding & No. of Patients \\
\hline Bowel Thickening & 6 \\
\hline Stricture & 6 \\
\hline Malrotation & 3 \\
\hline Tb & 3 \\
\hline Intussusception & 2 \\
\hline & \\
\hline
\end{tabular}




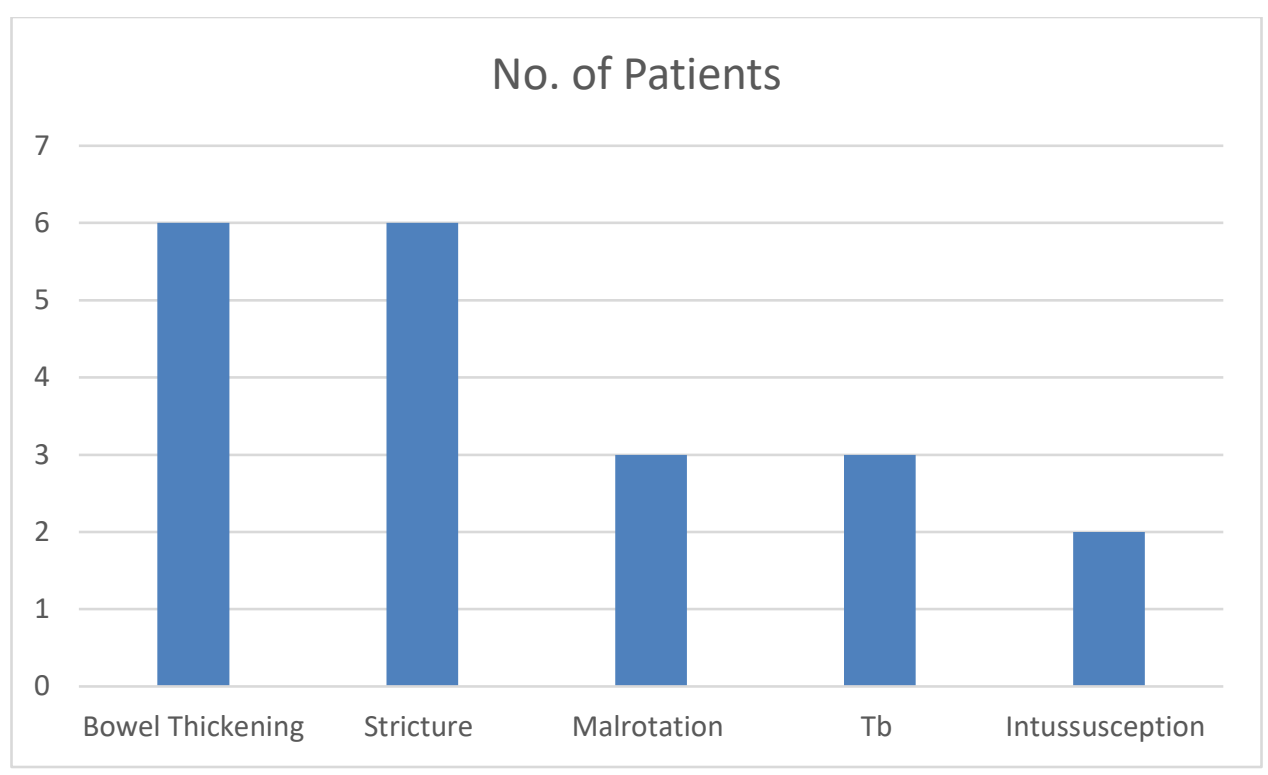

Figure 3:CT Scan Findings

Out of total, 20 patients were investigated based on CT scan, 6 patients had stricture, 6 had bowel thickening, 3 had malrotation, 3 had TB and 2 had intussusception.

We observed vital parameters and other parameters in conservatively managed patients. These parameters included abdominal tenderness, RT output, increased vomiting, and abdominal distention.

Those patients who showed signs of peritonitis, strangulation and haemodynamically instability were undergone surgical intervention. The average duration for surgically managed was 2.8 days. The average duration for conservatively managed patients was 2.9 days. In surgically managed patients, 4 had abdominal TB, 1 had intussusception, 8 had obstructed hernia, 11 had stricture, and 14 had adhesions.

We also compared demographic features based on presenting features and investigatory findings of patients who were conservatively managed and relieved. It was found that those who relieved conservatively, there was greater occurrence of history of abdominal surgery. For conservative management, time taken for relief ranged from 1 to 4 days after the admission with average of 2.9 days. Whereas, among surgically managed patients, time taken to relief was 1 to 4 days with average of 2.3 days.

Table 3: Comparison

\begin{tabular}{|l|c|c|c|}
\hline \multicolumn{1}{|c|}{ Variable } & $\begin{array}{c}\text { Conservatively } \\
\text { Managed Patients }\end{array}$ & $\begin{array}{c}\text { Surgically } \\
\text { Managed Patients }\end{array}$ & $\begin{array}{c}\text { P Value } \\
\text { (Chi } \\
\text { Square } \\
\text { Test }\end{array}$ \\
\hline Mean Age & 46.3 & 44.6 & 0.855 \\
\hline Male/Female Ratio & $3.8: 2$ & $2.3: 2$ & 0.105 \\
\hline Vomiting & 30 & 32 & 0.48 \\
\hline
\end{tabular}




\begin{tabular}{|l|c|c|c|}
\hline Obstipation & 32 & 33 & 0.441 \\
\hline Distension O/E & 28 & 36 & 1 \\
\hline Abdominal Lump & 0 & 3 & N.A. \\
\hline Visible Bowel Loop & 0 & 2 & N.A. \\
\hline P/H/O Abdo. Surgery & 6 & 24 & 0.01 \\
\hline Positive Sign of Peritonitis & 0 & 23 & N.A. \\
\hline
\end{tabular}

\section{CONCLUSION}

On the basis of the study, we conclude that common cause of SBO is the previously conducted surgery. We could not find any clear criteria for successful conservative management against the surgical management. Clinical decisions guide the management of SBO and timing of surgical intervention. Further study of methods for control and treatment of SBO is important because of its frequency, morbidity and cost in healthcare and patient's disability

\section{References}

1. Ahmed, M.N., Kaur, S.S., Zargar, H.U. (1984). Abdominal cocoon; an unusual cause of intestinal obstruction (a case report). Journal of Post Medical, 30, 62

2. Pandey, G.K., Agarwala, S., Chumber, S. (2005). Small Intestine Essentials of Surgery. New Delhi: JayPee Brothers.

3. Shelton, A.A., Thoedore, R.S., Welton, M.L. (2003). Small Intestine In: Way LW, Doherty GM, editors. Current Surgical Diagnosis and Treatment. New York: McGraw Hills.

4. Tumage, R.H., Heldmann, M., Cole, P. (2006). Intestinal Obstruction and Ileus. In: Feldman M, Friedman LS, Brandt LJf eds. Sleisenger \& Fordtran's Gastrointestinal and liver disease. Philadelphia: Saunders.

5. Whang, E.E., Zinner, M.J. (2005). Small Intestine. In: Charles BF, ed Schwartz principles of surgery. New York: McGraw Hill.

6. Winslet, M.C. (2004). Intestinal Obstruction. In: Russel RCG, Norman WS, Bulstrode Christopher JK, eds. Bailey \& Love's Short Practice of Surgery. London: Arnold. 